\title{
Response to 'Fear of death and the symmetry argument'
}

\author{
Natalja Deng \\ University of Cambridge \\ Faculty of Divinity \\ Cambridge, Cambridgeshire \\ United Kingdom of Great Britain and Northern Ireland \\ nmd24@cantabgold.net
}

Article info

CDD: 128.5

Received: 20.11.2016; Accepted: 21.11.2016

DOI: http://dx.doi.org/10.1590/0100-6045.2016.V39N4.ND

Keywords:

Symmetry argument

Lucretius

Death

Fear

\begin{abstract}
This article is a response to 'Fear of death and the symmetry argument', in this issue. In that article, the author discusses the above Lucretian symmetry argument, and proposes a view that justifies the existing asymmetry in our attitudes towards birth and death. I begin by distinguishing this symmetry argument from a different one, also loosely inspired by Lucretius, which also plays a role in the article. I then describe what I take to be the author's solution to the original symmetry argument (i.e. the one above) and explain why I am unpersuaded by it.
\end{abstract}

\section{Introduction}

The philosophy of time and the philosophy of death are connected in a number of interesting ways. One cluster of such connections has to do with some suggestive remarks of Lucretius'. Lucretius attempts to assuage our fear of death by drawing our attention to the likeness between the time before our births and the time after our deaths:

'Look back now and consider how the bygone ages of eternity that elapsed before our birth were nothing to us. Here, then, is a mirror in which nature shows us the time to come after our death.' (Lucretius, bk III, vv. 972-75)

Manuscrito - Rev. Int. Fil. Campinas, v. 39, n. 4, pp. 297-304, out.-dez. 2016. 
We can find in these remarks an argument about the reasonableness of certain attitudes (cf Johansson 2005) that goes as follows. Since past nonexistence and future nonexistence are in all relevant respects alike, our attitudes towards them should be the same; our attitude towards the former (and towards birth) isn't fearful; hence, our attitude towards the latter (and towards death) should also not be fearful.

This article is a response to 'Fear of death and the symmetry argument', in this issue. In that article, the author discusses the above Lucretian symmetry argument, and proposes a view that justifies the existing asymmetry in our attitudes towards birth and death. I begin by distinguishing this symmetry argument from a different one, also loosely inspired by Lucretius, which also plays a role in the article. I then describe what I take to be the author's solution to the original symmetry argument (i.e. the one above) and explain why I am unpersuaded by it.

\section{Badness versus fear}

The Lucretian style of argument has a lot going for it. Suppose two students of yours are alike in all relevant respects. If your attitude towards them nonetheless differs markedly, clearly something has gone wrong. Or suppose there are two airplane seats you have to choose between, and the two are in all relevant respects alike. If you feel (dis)inclined towards booking one, you should feel (dis)inclined towards booking the other. Your attitudes towards them should match.

Of course, the question now arises whether birth and death are in fact alike 'in all relevant respects'. This is the central issue that 'Fear of death and the symmetry argument' addresses, and I'll return to it shortly. But first it's useful to distinguish this symmetry argument from another symmetry argument.

That second symmetry argument is not about the reasonableness of attitudes at all; rather, it's about which events are (extrinsically) bad for one and why. It's directed against a particular account of the badness of death called deprivationism. According to deprivationism, death is bad for the one who dies iff, and to the extent that, it deprives that person of intrinsic goods he or she would have enjoyed had they not died. The argument goes as

Manuscrito - Rev. Int. Fil. Campinas, v. 39, n. 4, pp. 297-304, out.-dez. 2016. 
follows: If deprivationism is right, then birth too is bad for one, since by its lateness it deprives one of intrinsic goods one would have enjoyed had one been born earlier. But it isn't, so deprivationism is mistaken.

Although the two symmetry arguments are structurally similar, it's important to distinguish them. The first argument is about the reasonableness of fearful, or more generally negative emotional attitudes, while the second is about the (extrinsic) badness of death. Deprivationists usually insist on a substantial divide between what's bad for one and what it's all-thingsconsidered reasonable to feel distressed about. Not finding Aladdin's lamp is strictly speaking (extrinsically) bad for you, on deprivationism, but it needn't be something it would be all-things considered reasonable for you to feel badly about.

One might think the difference is not that important, especially if one disagrees with deprivationists on this last point and holds instead that 'fear of bad things is rational' (p. 2). ${ }^{1}$ However, keeping the arguments distinct also reveals just what needs to be done in order to counter the original symmetry argument (about the fear of death). Rather than having to first establish the badness of death, and then 'indicate a relevant asymmetry between the earlier and the later temporal limits of our life', one does not need to do the former. Rather, one needs only to do the latter, where the asymmetry one points to should be relevant to the reasonableness (or otherwise) of fearful attitudes.

In other words, providing a response to the original symmetry argument is a separate task from that of providing a response to the second symmetry argument directed against deprivationism. As an example of how this distinction becomes relevant, consider the author's remarks about the Nagelian response to the second symmetry argument. The idea here is that we couldn't have been born substantially earlier than we were, although we could die substantially later than we actually die. One's time of birth, but not one's time of death, is essential to one.

There are various problems with this deprivationist response (see e.g. Johansson 2005). However, the author maintains that the real problem with

\footnotetext{
1 Though in the context of a defense of deprivationism, which the author takes the article to be, this raises the further question of what to say about cases like Aladdin's lamp. Deprivationism seems to entail not finding it is (extrinsically) bad for one, but surely it's not rational to fear or otherwise feel badly about not finding it?
}

Manuscrito - Rev. Int. Fil. Campinas, v. 39, n. 4, pp. 297- 304, out.-dez. 2016. 
it is that 'even if it is correct, [the response] is too intricate and controversial to account for the common sense intuitive asymmetry between birth and death' (p. 6). Their reason for saying this is that they think any justification of attitudes has to be first and foremost an explanation of attitudes, and an explanation of attitudes has to be 'at least as obvious and widely accepted as the attitudes it seeks to explain' (p. 6).

Let's take these points in reverse order, starting with the final one, which resurfaces throughout the paper. Suppose one wants to explain why we don't fear prenatal nonexistence, and/or why there is this asymmetry in our attitudes i.e. we don't fear prenatal but do fear postmortem nonexistence. Is it the case that in order for one's explanation to be a good one, the explanation has to be obvious and widely accepted? It seems not: we need not be aware of the roots of our attitudes, nor of the roots of asymmetries in our attitudes, whether rational or not. For example, suppose part of the explanation of the asymmetry in our attitudes appeals to the wider asymmetry in our attitudes towards the past and the future. That wider asymmetry is ubiquitous, and an important aspect of our mental and emotional lives. But in order to have it, one need not be able to recognize that it obtains, much less understand its explanation. Most people fear their future dentist visits but not past ones; yet most people don't spend time worrying about the evolutionary or other origins of this asymmetry. Such an explanation may be correct, but it's not 'at least as obvious and widely accepted as the attitudes it seeks to explain'.

One might add to this that it's not clear that Nagel's line of thought is so very intricate and far removed from everyday thinking. Granted, everyday thinking may not involve explicit modal claims about birth and death, but something like the idea that we couldn't have been born earlier (but could die later) may, for all I know, be part of at least some people's default position.

Next, take the claim that a justification of attitudes, or asymmetries in attitudes, has to first and foremost be an explanation. In practice, a justification of attitudes may indeed need to take into account the explanation of how those attitudes come about. But prima face, these are again different tasks. Certainly one can explain without justifying.

Finally, again, the task of specifying why death but not birth can be bad for one is separate from that of justifying an asymmetry in our attitudes towards these two temporal limits of life. That's of course not to say that certain facts can't be equally well brought to bear on both tasks, and thereby

Manuscrito - Rev. Int. Fil. Campinas, v. 39, n. 4, pp. 297-304, out.dez. 2016. 
on both symmetry arguments. But keeping the distinction firmly in mind prevents us from throwing out approaches to one just because similar approaches to the other have not worked. Suppose the previous points persuade one that Nagel's claims don't lend themselves to either a convincing explanation or a justification of the asymmetry in our attitudes. Why should that mean they can't figure in a deprivationist response to the second symmetry argument? If they secured that deprivationism did not imply that (late) birth is bad for one, they would figure in such a response.

This is one instance where the distinction between the arguments matters.

\section{The temporal limits of life}

Since the author's main concern is to justify the asymmetry in our attitudes towards birth and death, respectively, it's appropriate to take the article to be mainly a response to the first symmetry argument. From now on, I will focus on that aspect of the discussion.

The author suggests that the answer to the (original) symmetry argument 'should be found in a well-known contingent fact about the development of living creatures in general and human beings in particular' (p. 16). This is the fact that 'having a beginning is a nomologically necessary condition for life', i.e. that living beings must begin to exist. ' $[\mathrm{L}]$ ife as we know it cannot exist without having a beginning' (p. 17). The reason this is supposed to help with the symmetry argument is that the same is not true of death. While de facto, living beings both begin and cease to exist, one of these temporal limits of life is necessary and the other contingent, according to the author:

'All human beings are mortal, and their lives come to an end at one point or another. However, in contrast to birth, this contingent fact seems nomologically unnecessary and therefore avoidable. To begin with, although the biological process which marks the beginning of life is similar in all human beings, the processes which put an end to human lives are different from person to person. Some die due to grave bodily harm, others die from

various diseases, and there are those who die from general deterioration caused by old age. [...] Indeed, it is easy to imagine a possible continuation of any human life, simply by imagining the absence of any disease or bodily harm which might bring this life to an end, or by imagining that the process of

Manuscrito - Rev. Int. Fil. Campinas, v. 39, n. 4, pp. 297-304, out.-dez. 2016. 
deterioration which is associated with old age is slowed down or even completely stopped.' (p. 17/8) ${ }^{2}$

In short, the author's response to the (original) symmetry argument is that birth, but not death, is nomologically necessary, and hence unavoidable; this is the relevant asymmetry between the two temporal limits of life, and it is why it is reasonable to have asymmetric attitudes towards them. In particular, it's reasonable to only fear one of them, namely the avoidable one, death.

While birth is viewed as a nomologically necessary condition for life, and therefore is seen as a blessing, death is viewed as a nomologically unnecessary, and therefore possibly avoidable, limit to life. This asymmetry not only explains the fear of death, and the joy of birth, but also justifies these basic human attitudes.' (p. 20)

The first problem I see with this is that the author gives us no good reason to think that the asymmetry in question obtains. That is, we are given no good reason to think that life as a matter of biological necessity has to have a beginning, but doesn't have to have an end. The author says that people die in different ways, while they are all born, and grow up the same way. Granted that there is more variation in the former, since people die of very different causes. But this is irrelevant to whether or not they must, in some way, all die. Neither birth nor death is metaphysically necessary, so they are contingent in that sense; but if birth is biologically necessary, why not death? It seems just as much an inescapable part of biological reality.

Moreover, even if one assumed for the sake of discussion that imaginability was a good general guide to biological possibility, the asymmetry in question again does not seem to result. We can imagine away any particular cause of death, and we can even imagine immortality. But we can also imagine having always existed (whether or not we are inclined to imagine this), as the author himself invites us to do at some point in the discussion: [T] he relevant idea for the current discussion is the idea of an infinite past of individuals,

\footnotetext{
${ }^{2}$ In places, the author describes the fact instead as concerning what we think is the case regarding the modal status of birth and death: 'While the earlier limit of our life is viewed as [my emphasis] a nomologically necessary condition for life, the later limit of life is not a nomologically necessary condition for life, and is therefore an unnecessary limitation of life' (p. 18). These claims are best kept apart (and I will focus on the previous version).
}

Manuscrito - Rev. Int. Fil. Campinas, v. 39, n. 4, pp. 297-304, out.-dez. 2016. 
and indeed there are traditions which believe in reincarnation, and in some versions of the doctrine, there are infinitely many past incarnations' (p. 16).

The second problem with this solution is that it's not clear that the asymmetry, if it obtained, would be of the right kind. The key idea of the (original) symmetry argument is that past and future nonexistence are equally fear-worthy (namely not very), because they are alike in all relevant respects (e.g. neither can affect us negatively, cause us pain, etc.). Now suppose the main relevant respect in which they differ is that past nonexistence has to happen, while future nonexistence just happens. It's not clear what bearing this, by itself, has on how comparatively fear-worthy they are. If there is a connection, why not think that what has to happen, and is 'unavoidable', is rather more fear-worthy than what just happens and is 'avoidable'? Suppose two tigers run towards you, and only one looks avoidable; shouldn't the other one scare you more?

Perhaps the author would object that while two tigers are equally fearworthy to begin with, birth and death are not. But that is just what we need a reason to think, in order to answer the (original) symmetry argument.

\section{Concluding remarks}

The Lucretian tries to assuage our fear of death by pointing to the similarity between prenatal and postmortem nonexistence. Relevantly similar things deserve an equal emotional response. Birth and death are similar in all relevant respects, so our attitudes towards them should match. For all we've said here, this may be right. However, as Johansson (2005) emphasizes, the symmetry argument only gets us to the conclusion that our attitudes towards birth and death should match, not that they shouldn't be fearful. The next question would then be why we shouldn't fear prenatal nonexistence too. ${ }^{3}$

\footnotetext{
3 Acknowledgement: This response was written while I was a member of the Templeton World Charity Foundation project 'Theology, Philosophy of Religion, and the Natural Sciences'.
}

Manuscrito - Rev. Int. Fil. Campinas, v. 39, n. 4, pp. 297-304, out.-dez. 2016. 


\section{References}

Johansson, J. Mortal Beings: On the Metaphysics and Value of Death. Stockholm: Almqvist \& Wiksell International, 2005.

LUCRETIUS On the Nature of Things, Translated by Martin Ferguson Smith, Cambridge: Hackett, 2001. 